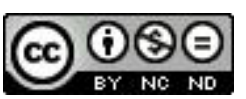

\title{
O que é número? Produção, circulação e apropriação da Matemática Moderna para crianças
}

\author{
What is a number? \\ Production, circulation and appropriation of a New \\ Math for children
}

Wagner Rodrigues Valente*

\begin{abstract}
Resumo
O estudo aborda as mudanças nos conteúdos a serem ensinados nos primeiros anos da escola elementar. Em particular, considera o ensino de matemática. Atém-se, sobretudo, à emergência da Matemática Moderna no Brasil. De forma específica, analisa o conceito de número. Leva em consideração, como base teórico-metodológica, estudos vindos da História Cultural. Na análise realizada trata de movimentos pedagógicos anteriores ao que fica conhecido como Movimento da Matemática Moderna: o ensino tradicional, o ensino intuitivo e o escolanovismo. Em seguida, leva em conta a emergência, divulgação e apropriação de uma nova matemática escolar a partir de finais da primeira metade do século XX. O artigo orienta-se pela seguinte questão: que alterações o conceito de número sofre, na matemática escolar brasileira, em finais da década de 1950? Como resultado do estudo revela-se como se dá o processo de produção, de circulação e de apropriação de novos conteúdos elementares da matemática escolar para crianças.
\end{abstract}

Palavras-chave: Ensino Primário. Aritmética. Movimento da Matemática Moderna. Número.

\footnotetext{
"Livre Docente pelo Departamento de Educação da Universidade Federal de São Paulo (UNIFESP). Coordenador do Grupo de Pesquisa de História da Educação Matemática (GHEMAT) (www.unifesp.br) centros/ghemat). Endereço para correspondência: Estrada do Caminho Velho, 333, Bairro dos Pimentas, CEP: 07252-312, Guarulhos, SP, Brasil. E-mail: wagner.valente@unifesp.br.
} 


\begin{abstract}
This study addresses content changes to be taught in the first years of elementary school. In particular, it considers the teaching of mathematics with a focus on the emergence of Modern Mathematics in Brazil. In a specific way, it examines the concept of number. It considers as a theoretical and methodological foundation studies originally from cultural history. The analysis considers the pedagogical movement prior to what is known as the Modern Mathematics Movement: traditional education, intuitive teaching and progressive era in education. It then takes into account the emergence, dissemination and appropriation of a new mathematics for schools in the [mid-20th Century / 1940s]. The article is guided by the following question: what changes does the concept of number undergo in the mathematics for schools in the late 1950s? As a result the study reveals how the production, distribution and appropriation of new mathematics content for children of elementary school took place.
\end{abstract}

Keywords: Primary Education. Arithmetic. Modern Mathematics Movement. Number.

\title{
1 Introdução
}

Este estudo aborda as transformações, ao longo do tempo, do saber escolar. Analisa, historicamente, as mudanças nos conteúdos a serem ensinados nos primeiros anos da escola elementar. Em particular, considera o ensino de matemática. Atém-se, sobretudo, à emergência da Matemática Moderna. De forma específica, analisa o conceito de número. Construído em partes, o estudo apresenta, de início, o ferramental teórico-metodológico utilizado na pesquisa das alterações da matemática escolar. Em seguida, trata de movimentos pedagógicos anteriores ao que fica conhecido como Movimento da Matemática Moderna: o ensino tradicional, o ensino intuitivo e o escolanovismo. Na análise dessas vagas pedagógicas, focaliza o conceito de número e seu significado para a cultura escolar de cada uma dessas épocas. Por fim, analisa a emergência, divulgação e apropriação de uma nova matemática escolar a partir de finais da primeira metade do século XX. O artigo orienta-se pela seguinte questão: que alterações o conceito de número sofre, na matemática escolar, em finais da década de 1950? Procurar-se-á mostrar, a partir do estudo dessas alterações, em perspectiva histórico-cultural, como se dá o processo de produção, de circulação e de apropriação de novos conteúdos elementares da matemática escolar para crianças. 


\section{História Cultural, História das Disciplinas Escolares e questões epistemológicas}

Dada a sua complexidade e extensão, não é tarefa simples caracterizar, em poucas linhas, como se dá a pesquisa que tem por referência a História Cultural. No entanto, algumas balizas parecem indicar o caminho a seguir nesses estudos. Uma delas refere-se ao tratamento dado ao termo cultura. O historiador francês Roger Chartier menciona haver duas famílias de significados para ele: uma delas é a que designa por cultura as obras e os gestos que, em uma dada sociedade se subtraem das urgências do cotidiano para submeterem-se a um juízo estético ou intelectual; a outra família se refere às práticas ordinárias através das quais uma sociedade ou um indivíduo vivem e refletem sobre sua relação com o mundo, com os outros ou consigo mesmo (CHARTIER, 2007, p. 50). Assim, considerando esta segunda acepção, que toma a noção de cultura agarrada a um grupo e à sua vida comum de existência, é que nos localizamos no âmbito de uma História Cultural; em específico, à vida cotidiana das escolas, aos significados construídos no meio escolar que dão vida e funcionamento ao diaa-dia pedagógico. Ou seja, ao que se pode chamar de cultura escolar. E, nesse contexto, interessam as transformações ao longo do tempo que ocorrem com a matemática nela presente: a matemática escolar.

Faz já mais de uma vintena de anos que um texto de André Chervel vem constituindo referência fundamental para o estudo das disciplinas escolares ${ }^{1}$. Esse pesquisador traz contribuição fundamental, a partir de suas pesquisas sobre a gramática escolar francesa, à análise dos conteúdos escolares. Chervel, de modo original, analisa historicamente as relações entre ciência, pedagogia e as disciplinas escolares. Para Chervel, a forma consagrada de tratamento dos ensinos escolares pode ser sintetizada, considerando-se que:

$\mathrm{Na}$ opinião comum, a escola ensina as ciências, as quais fizeram suas comprovações em outro local. Ela ensina à gramática porque a gramática, criação secular dos linguistas, expressa a verdade da língua; ela ensina as ciências exatas, como a matemática, e, quando ela se envolve com a matemática moderna é, pensa-se, porque acaba de ocorrer uma revolução na ciência matemática; ela ensina a história dos historiadores, a civilização e a cultura latina da Roma antiga, a filosofia dos grandes filósofos, o

\footnotetext{
${ }^{1}$ Trata-se do artigo intitulado História das disciplinas escolares: reflexões sobre um campo de pesquisa, publicado em português em 1990.
} 
inglês que se fala na Inglaterra ou nos Estados Unidos, e o francês de todo o mundo. (CHERVEL, 1990, p. 180).

Contrapondo-se a essa concepção comum, os estudos de Chervel apontam a originalidade das produções escolares, em termos de elaboração das disciplinas. Elas são o resultado histórico do que a escola produz ao longo dos séculos de sua existência. E, mais: ajunte-se a isso, uma verdadeira revolução epistemológica na forma de analisar os conteúdos escolares. O tema surge quando o autor aborda as relações entre ciência, pedagogia e disciplinas escolares. A concepção comum existente sobre os ensinos escolares, mencionada anteriormente, ancora-se, igualmente, num modo clássico de perceber a pedagogia: um lubrificante que age sobre os conteúdos produzidos pela comunidade científica, de modo a vulgarizar a ciência para crianças e adolescentes. Tratar-se-ia de uma metodologia, de modos de trabalhar os conteúdos de maneira a que pudessem ser ensinados. Segundo essa visão, de um lado estão os conteúdos científicos e, de outro, os métodos. Em suma: Ciências apartadas da Pedagogia.

No entanto, o trabalho de André Chervel rompe com essa perspectiva à medida que alerta para o fato de que:

Excluir a pedagogia do estudo dos conteúdos é condenarse a nada compreender do funcionamento real dos ensinos. A pedagogia, longe de ser um lubrificante espalhado sobre o mecanismo, não é senão um elemento desse mecanismo; aquele que transforma os ensinos em aprendizagens (CHERVEL, 1990, p. 182).

Este texto adota essa postura teórico-metodológica. Desse modo, não separa método e conteúdo, pedagogia e ciência na escola, matemática e pedagogia. Estuda a matemática escolar: elemento produzido historicamente no embate da cultura escolar com outras culturas, esta constituída do imbricamento inseparável de métodos e conteúdos definidores da matéria a ensinar. Em específico, este texto analisa o conceito de número e sua transformação na passagem do que é conhecido como Movimento da Matemática Moderna. Para essa empreitada, o estudo retoma épocas anteriores, de vigência das pedagogias ditas tradicionais, intuitivas e escolanovistas. 


\section{O que é número? Tradição, intuição e escolanovismo: preâmbulos da modernidade.}

\section{Tudo indica que é no surgimento do movimento pedagógico denominado} ensino intuitivo, que fica primeiramente constituída a representação de ensino tradicional. A chegada dessa vaga pedagógica se dá no contraponto ao que é considerado como velha pedagogia. Com a construção da representação do passado, do antigo, afirma-se o novo, num embate, numa luta de representações 2 . Sobretudo da lavra de Rui Barbosa ${ }^{3}$, emerge e consolida-se a representação do ensino tradicional: trata-se de um ensino livresco, de repetição por processos mecânicos ${ }^{4}$.

$\mathrm{Na}$ afirmação da nova pedagogia intuitiva é imperativo abandonar as formas antigas do ensino dos conteúdos escolares. Longe deve ficar o tratamento

\footnotetext{
${ }^{2}$ Cabe, neste ponto, mencionar os estudos do historiador Roger Chartier sobre história cultural e o papel das representações. De pronto, explicitar o que o autor entende por representação: uma noção que articula três modalidades da relação com o mundo social: em primeiro lugar, o trabalho de classificação e de delimitação que produz as configurações intelectuais múltiplas, através das quais a realidade é contraditoriamente construída pelos diferentes grupos; seguidamente, as práticas que visam fazer reconhecer uma identidade social, exibir uma maneira própria de estar no mundo, significar simbolicamente um estatuto e uma posição; por fim, as formas institucionais e objetivas graças às quais uns "representantes" (instâncias coletivas ou pessoa singulares) marcam de forma visível e perpetuada a existência do grupo, da classe ou da comunidade (CHARTIER, 1990, p. 23). Cabe, ainda, trazer os estudos do autor, no que toca às lutas de representação. Diz Chartier: "As percepções do social não são de forma alguma discursos neutros: produzem estratégias e práticas (sociais, escolares, políticas) que tendem a impor uma autoridade à custa de outros, por elas menosprezados, a legitimar um projeto reformador ou a justificar, para os próprios indivíduos, as suas escolhas e condutas. Por isso esta investigação sobre as representações supõe-nas como estando sempre colocadas num campo de concorrências e de competições cujos desafios se enunciam em termos de poder e de dominação. As lutas de representações têm tanta importância como as lutas econômicas para compreender os mecanismos pelos quais um grupo impõe, ou tenta impor, a sua concepção do mundo social, os valores que são os seus, e o seu domínio" (CHARTIER, 1990, p. 17). ${ }^{3} \mathrm{Na}$ chegada do ideário do ensino intuitivo destaca-se, em primeiro lugar, o estudo de fôlego de Rui Barbosa. Nas centenas de páginas que escreve como relator, da Comissão de Instrução Pública encarregada de apreciar o Decreto n. 7.247, de 19 de abril de 1879, de autoria do ministro Carlos Leôncio de Carvalho - que reformava o ensino primário e secundário no município da Corte e o ensino superior em todo o Império - coloca a necessidade do Estado assumir total responsabilidade para com a oferta da educação, desde o jardim de infância até o ensino superior.

${ }^{4}$ Os pesquisadores Antonio Miguel e Denise Vilela caracterizam esse tempo escolar como uma etapa inicial, cunhada como mnemônico-mecanicista. Assim, "as perspectivas mnemônico-mecanicistas parecem ter predominantemente orientado os processos escolares de mobilização de cultura matemática na escola primária, em nosso país, durante toda a fase imperial. Embora a memória aqui entendida não como uma faculdade ou processo mental, mas como uma característica inerente aos processos de comunicação humana e resultante do aperfeiçoamento desses mesmos processos na história - seja imprescindível para a realização de todas as atividades humanas, sabemos, entretanto, que o seu papel foi e continua sendo superdimensionado nos processos escolares de mobilização de cultura matemática. De certo modo, essa supervalorização da memória nos processos de aprendizagem humana parece remontar a Platão" (MIGUEL; VILELA, 2008, p. 99).
} 
da aritmética de modo tradicional. Decorar mecanicamente tabuadas, cantá-las sem compreender os seus resultados é algo que, parodiando Barbosa, "cumpre erradicar" (BARBOSA, 1946, p. 36). E como ultrapassar o modo tradicional de ensinar Aritmética?

A chegada do ideário do ensino intuitivo, como experimental e concreto, constrói uma representação do passado do ensino de Aritmética no primário, profundamente negativa. Trata-se de um ensino abstrato, com uso quase exclusivo de processos de memorização, sem utilidade. Também ela, a Aritmética, imersa nessa escola ineficiente, deve ser transformada. Ensinada de outro modo, com materiais onde o ensino possa ser o mais concreto possível.

O ensino intuitivo da Aritmética, da numeração, levará em conta a Lição de Coisas. Assim, cada número, tratado inicialmente de modo oral, será gravado nas mentes infantis, associando-o sempre às coisas. As coisas darão lições sobre os números ${ }^{5}$.

Na nova vaga pedagógica do ensino intuitivo número continua sendo indicador de quantidade, do mesmo modo que em tempos anteriores, caracterizados como sendo de uma pedagogia tradicional. Mas, esse indicador de quantidades, na nova pedagogia intuitiva deve ser ensinado logo de início, na contagem de coisas da vida cotidiana. E elas têm que ter natureza que toque os sentidos do aprendiz: uma quantidade a ser sentida.

A vaga do ensino intuitivo sustenta-se na relação de contraponto que mantém com antigas práticas pedagógicas. Não está em debate se o antigo está plenamente em conformidade com épocas em que a memorização e repetição constituem expedientes pedagógicos para o ensino e aprendizagem. A caracterização do passado se dá como um tempo onde práticas consideradas

\footnotetext{
5 "As lições de coisas, forma pela qual o método de ensino intuitivo foi vulgarizado é, na realidade, a primeira forma de intuição - a intuição sensível. O termo foi popularizado pela Mme. PapeCarpentier e empregado oficialmente durante suas conferências proferidas aos professores presentes na Exposição Universal de Paris, em 1867. Pestalozzi também é apontado como referência em lições de coisas, pelo fato deste ter captado os pontos essenciais da renovação pedagógica que as lições preconizavam "[...] as coisas antes das palavras, a educação pelas coisas e não a educação pelas palavras". Despertar e aguçar o sentido da observação, em todas as idades, em todos os graus de ensino, colocar a criança na presença das coisas, fazê-las ver, tocar, distinguir, medir, comparar, nomear, enfim, conhecê-las, este é o objetivo das lições de coisas no ensino primário e nos jardins de infância, cuja aplicação pode ser feita através de dois sistemas: como um exercício à parte ou uma lição distinta, tendo uma hora reservada para aplicação dentro do programa de ensino ou aplicada em todas as disciplinas escolares, inserida em todo programa de ensino. Sua difusão, no final do século XIX, gerou a produção de um grande número de manuais escolares para o ensino das lições de coisas, dentre eles podemos citar: Primeiras Lições de Coisas de Norman Allison Calkins, publicado originalmente nos Estados Unidos, em 1861 e traduzido por Rui Barbosa, em 1886 (...). Disponível em: http://www.histedbr.fae.unicamp.br/navegando/glossario/verb_c_licoes_das_coisas.htm GLOSSÁRIO - Acesso em: 26 jan. 2012).
} 
erradas têm lugar. A velha pedagogia tradicional é errada. Na desqualificação do passado, revela-se a estratégia mais utilizada para dar visibilidade a novos tempos de práticas de ensino intuitivas.

Na chegada da pedagogia intuitiva pode-se ler a mudança, na matemática escolar, do conceito de número: de quantidade a ser memorizada, a conceituação de número passa a quantidade a ser sentida. Pouco importa do ponto de vista escolar - qual seja a concepção matemática de número: Seu papel no ensino é seu próprio definidor! Importa o significado que tenha para a cultura escolar. Passa-se de uma representação de que a escola tradicional promovia a aprendizagem de número pela sua característica de quantidade a ser memorizada, para aquela em que o conceito de número a ser aprendido é o de quantidade a ser sentida, nos moldes da pedagogia intuitiva. E essa não é uma alteração externa, somente de metodologia, lubrificando de outro modo o ensino de número: trata-se de uma alteração epistemológica no âmbito da cultura escolar, da construção de outro significado para esse saber e esse conceito.

Novos ventos pedagógicos sopram do estrangeiro, e uma nova pedagogia se instala: chegam os tempos de Escola Nova. Em termos educacionais, os ecos do final da I Guerra Mundial chegam ao Brasil, através de novas ideias vindas dos Estados Unidos e dos países europeus. O ideário que aporta em terras brasileiras reforça "os fins político-sociais da escola e [sobre] o poder da educação como instrumento de reconstrução social, política e moral". A educação passa a instrumento de "manutenção da paz e compreensão entre os homens" (TANURI, 1979, p. 153). Para que cumpra papel tão fundamental faz-se necessário repensar a educação, rever o ensino. Entra-se num período de dar ao processo educativo novas bases, novos paradigmas. Surge a renovação pedagógica e o desafio de romper com os modos considerados tradicionais. Há necessidade de outros métodos e programas. Emerge um novo modo de pensar o papel do professor no processo educativo: a criança deve ser o centro do ensino. O saber psicológico surge como condutor da pedagogia.

Caberia a Lourenço Filho fazer, de modo o mais claro possível, a distinção dos novos tempos pedagógicos. O educador - um dos ícones da Escola Nova no Brasil - tem a tarefa de marcar a diferença da era do ensino intuitivo - das lições de coisas, e os novos métodos da pedagogia do escolanovismo. Essa iniciativa pode ser lida nos esclarecimentos dados por esse educador, no início dos anos 1930, ao ser questionado sobre a reforma da Instrução Pública que promove no nordeste brasileiro ${ }^{6}$ :

${ }^{6} \mathrm{O}$ trabalho de CARVALHO (2002) detalha o contexto em que Lourenço Filho é instado a marcar a diferença de suas ações no âmbito do escolanovismo no contraponto com a herança da escola das lições de coisas, do método intuitivo. 
A princípio todo o ensino era verbal. Acreditava-se na magia da palavra, supunha-se mesmo que ela transmitisse as ideias. Foi ainda um pouco o ensino que aí eu encontrei [...]. Depois do movimento filosófico da Renascença, apareceu a nova concepção de formação genética do espírito: nada está na inteligência que não tivesse passado pelos sentidos. Como consequência direta, o ensino de coisas, pelas coisas, ou intuitivo. Quanto tempo levou a implantar-se? Séculos e séculos, e ainda não dominou todas as escolas. Do começo deste século para cá, essa concepção tende a ser substituída por outra, a de uma filosofia pragmatista (a verdade é utilidade), e de uma filosofia vitalista (além das impressões sensoriais há um quid, em cada indivíduo, que plasma as ideias a sua feição). O próprio pensamento para essa escola é ação: ação reduzida, mas ação. Ação reduzida e sistematizada pela linguagem, mas atividade. Daí, como consequência, não se pretender ensinar mais tão somente pela ação das coisas, mas pela ação do indivíduo, único capaz de organizar o espírito solidamente, para o seu fim normal: dirigir a ação (LOURENÇO FILHO, 1934 apud CARVALHO, 2002, p. 385-386).

A essa caracterização e distinção que faz Lourenço Filho, evocando, sobretudo, o ensino intuitivo e aquele da Escola Nova, através de uma filosofia pragmatista e de uma filosofia vitalista cabe perguntar: Como esse ideário é utilizado para reconstruir os ensinos de matemática na escola primária? Buscando os periódicos pedagógicos, que fizeram circular a nova pedagogia entre os professores, é possível responder a esta questão. Notar-se-á que, para o ensino de matemática surge fortemente a concepção que ele deverá ser realizado através da resolução de problemas. E esses problemas são considerados como situações da vida real do aluno. Eles, os problemas, farão a ligação do ensino com a vida, com a nova filosofia orientadora da escola ativa.

A divulgação do novo ideário pedagógico escolanovista ganha as páginas dos periódicos pedagógicos. Exemplo ilustrativo é o artigo publicado em 1934, pela Revista Brasileira de Pedagogia, editada no Rio de Janeiro, como órgão oficial da Confederação Católica Brasileira de Educação: "Algumas considerações sobre o ensino da Aritmética". A autora do texto divulga um novo modo de ensinar Aritmética e faz sugestões que impliquem na ligação desse saber com a vida das crianças. O artigo, assinado pela professora Zulmira de Queiroz Breiner (1934, p. 261) da Escola Normal de Curvelo, MG, conclui que 
nas propostas daquela atualidade, "a Arithmetica deixou de ser tipicamente abstrata para ser ciência experimental, não só porque a criança não compreende abstrações, como porque os vários princípios matemáticos surgem da experiência".

Vários outros exemplos de artigos oriundos dos periódicos pedagógicos poderiam ser mencionados para sustentar, empiricamente, a afirmação do surgimento de um novo discurso sobre o significado do ensino de matemática para crianças. E, dentre essa nova pedagogia, é reconstruído o conceito de número. Permanece a ideia de número como quantidade. Mas, para a escola ativa, para o escolanovismo em matemática, número não mais é algo que movimenta a aprendizagem do aluno através do sentir as coisas externas a ele. As coisas não ensinam o que é número. Como preconiza Lourenço Filho, a aprendizagem virá da ação dos alunos na vida real, de sua atividade, da experiência com o seu meio. No caso do ensino de matemática, essa ação terá origem naquilo que os discursos direcionados a professores, contidos nas revistas pedagógicas, passam a caracterizar como resolução de problemas da vida real ${ }^{7}$.

Esse discurso parece ter vida longa. O Programa de Aritmética de 1949, orientador do ensino primário no estado de São Paulo, coloca, dentre os quatro objetivos, o seguinte:

Preparar a criança para a vida, tornando-a capaz de resolver os seus problemas todas as vezes que impliquem o uso do cálculo e da medida; Desenvolver a habilidade de analisar e resolver problemas simples, relacionados com as experiências de sua vida infantil e, desde ceda, interessa-la nos problemas econômicos da família e do ambiente em que vive, tornando, assim o ensino prático e educativo (SÃO PAULO, 1949 apud LEME DA SILVA, 2011).

Em meados dos anos 1950, em livro de metodologia para o ensino de matemática no curso primário, a professora-autora Irene de Albuquerque, catedrática de Prática de Ensino do Instituto de Educação do Distrito Federal,

\footnotetext{
${ }^{7}$ Como impulsionadores da vaga escolanovista na matemática escolar, inúmeros são os artigos publicados sobre essa temática, nos periódicos pedagógicos editados durante a década de 1930. Citese, por exemplo: pela Revista do Ensino, da Diretoria da Instrução do Estado de Minas Gerais, os artigos de 1933: "O ensino da Aritmética e a resolução dos problemas", "Os problemas"; pela Revista Brasileira de Pedagogia, da Confederação Católica Brasileira de Educação, Rio de Janeiro, os textos publicados em 1937, "Metodologia do Ensino da Arithmetica" e "Metodologia dos problemas"; pela Revista do Professor, do Centro do Professorado Paulista, em texto publicado em 1934, "Erros no ensino da Aritmética elementar".
} 
logo à Introdução da obra, postula:

Toda criança de inteligência normal, sem ser brilhante, é capaz de aprender, com relativo êxito, as noções dos programas de Matemática da escola primária; pode, ainda, resolver com certa facilidade os problemas de Matemática que a vida lhe apresenta (ALBUQUERQUE, 1960, p. 7).

Deixando os alunos se envolverem com esses problemas, eles viverão situações e aprenderão matemática, aritmética e o conceito de número. E, assim, número passará a ser uma quantidade vivida pelo educando, muito além da experiência sensível, preconizada pela vaga intuitiva.

Pedagogia Tradicional, Intuitiva, Escola Nova e tantas outras pedagogias, não tratadas anteriormente, carregam concepções de ensino e de aprendizagem. Elaboram e reelaboram matérias e disciplinas escolares, constroem e reconstroem os saberes escolares.

Como ocorrem as transformações da matemática escolar e, mais especificamente, aquelas ligadas ao conceito de número, presente no cotidiano escolar, na vigência das diversas pedagogias que antecedem os tempos do Movimento da Matemática Moderna? Como se procurou mostrar anteriormente, mesmo de maneira abreviada, na passagem do tempo, o significado desse conceito revela quantidade, mas com adjetivações diferentes. No que toca a seu significado, para as práticas escolares, número é quantidade memorizada, sentida e vivida. Esses termos expressam a trajetória de mudança de significados para número. E essa mudança liga-se, diretamente, às transformações da cultura escolar ${ }^{8}$. Essa dinâmica altera-se, radicalmente, em finais da década de 1950.

\section{A produção de um modelo cultural: a modernidade da matemática para crianças}

Os tempos são de estruturalismo. O estruturalismo como método rigoroso de análise intelectual, que traz grande esperança de fazer avançar temas científicos fundamentais. O estruturalismo como tratamento das relações entre

\footnotetext{
${ }^{8}$ Um estudo de maior fôlego, sobre o tratamento do ensino de número no curso primário, em tempos anteriores ao Movimento da Matemática Moderna, remete à pesquisa de doutoramento de David Antonio da Costa. Nela, o autor analisa com profundidade as transformações de número levando em conta os livros didáticos publicados em finais do século XIX até o final da década de 1940. Nesse estudo, Costa (2010) mobiliza Pestalozzi, Grube, Parker, Dewey e as concepções pedagógicas originadas desses autores na escrita de obras para o ensino de Aritmética nos anos iniciais, mostrando, sobretudo, a passagem da memorização para o ensino intuitivo.
} 
as partes e o todo. A totalidade com prioridade lógica sobre as partes, e as relações sendo mais importantes que as entidades que lhes são vinculadas. A estrutura oculta sendo, sempre, mais importante que o evidente. O simbolismo como relevante e não as entidades simbolizadas. Assim, o estruturalismo ganha status interdisciplinar e multidisciplinar na produção de conhecimentos na matemática, na filosofia, na linguística, na antropologia, na crítica literária. Transforma-se em filosofia dominante, em meados do século XX, um momento particular da história do pensamento humano, um tempo forte da consciência crítica (DOSSE, 1992, p. 9) .

As primeiras ideias que dão forma à revolução estruturalista começam a germinar durante o período de entreguerras, com os membros do Círculo Linguístico de Praga, cuja figura principal é o linguísta russo Roman Jakobson. O termo estrutura começa a ser utilizado por esse grupo em 1929. Seis anos mais tarde, constituindo-se como um grupo de matemáticos, Bourbaki ${ }^{9}$ se apropria dele. O uso e caracterização matemática da ideia de estrutura é, em parte, responsável por sua adoção na psicologia. Jean Piaget interessa-se pela matemática e, assim, as ideias de Bourbaki lhe são úteis. Piaget chega à conclusão de que, em todos os estágios do desenvolvimento da inteligência nas crianças, os processos de pensamento se organizam de forma muito estruturada segundo noções matemáticas definidas com grande precisão por Bourbaki. Piaget considera que as estruturas mentais que permitem com que adolescentes e adultos pensem de forma lógica, tomam como modelo estruturas matemáticas (ACZEL, 2009, p. 115-116 e 139).

Os marcos de aproximação da psicologia genética com a matemática estruturalista são estabelecidos no encontro de Piaget com Dieudonné:

Assim como André Weil e Claude Lévi-Strauss se encontraram em Nova York, Jean Piaget e Jean Dieudonné também estiveram em contato. Esta relação marcou profundamente a evolução da ciência, reforçando a influência exercida por Bourbaki no avanço do estruturalismo. A reunião teve lugar em abril de $1952 \mathrm{em}$ um congresso de estruturas matemáticas e estruturas mentais celebrado nas imediações de Paris. Dieudonné deu uma

\footnotetext{
${ }_{9}^{9}$ Nicolas Bourbaki é o nome de um grupo de matemáticos organizados numa associação, na França, que tem por objetivo, a partir de sua formação, em 1935, conduzir o ensino de matemática de forma rigorosa. Bourbaki é referência maior na organização estrutural das matemáticas. Jean Dieudonné (1906-1994) é um dos membros mais ativos e produtivos do Grupo. Dieudonné escreve numerosas obras, e é autor importante de história da matemática, onde contribui muito na consolidação de certa ortodoxia estruturalista (PATRAS, 2001, p. 6).
} 
conferência aonde descreveu as três estruturas-mãe de Bourbaki: composição, proximidade e ordem (estruturas algébrica, topológica e de ordem). Em seguida, Piaget tratou das estruturas que havia descoberto para explicar a construção do pensamento das crianças. Para surpresa de ambos os conferencistas, ficou claro que tratavam do mesmo assunto. Pareceu óbvio que existia uma relação direta entre as três estruturas matemáticas estudadas por Bourbaki e aquelas inerentes ao pensamento operativo das crianças (ACZEL, 2009, p. 140).

Esse encontro parece ser emblemático. Mas, antes e depois dele, outros eventos na Europa propiciam discussões entre matemática e psicologia, nesses novos tempos estruturalistas. São seminários internacionais organizados pela Commission internationale pour l'étude et l'amélioration del'ensegnement des mathématiques. Em 1955, essa Comissão publica, como obra coletiva, o texto L'Enseignement des Mathématiques. Como autores estão "seis de seus membros fundadores: um psicólogo, um lógico matemático, três matemáticos profissionais e pedagogo das matemáticas" (PIAGET et al., 1955, p. 5-7). Pela ordem: J. Piaget, E. W. Beth, J. Dieudonné, A. Lichnerowicz, G. Choquet e C. Gattegno. O primeiro capítulo do livro intitula-se Les structures mathématiques et les structures opératoires de l'intelligence. Tal texto constitui síntese da comunicação de Jean Piaget feita no seminário de 1952.

Ao que tudo indica, esses seminários transformam-se em ponto inicial e de apoio ao que vem em seguida, com amplo financiamento e divulgação internacional, com vistas à transformação da matemática escolar. Em 1959, a OECE - Organização Europeia de Cooperação Econômica promove um inquérito relativamente ao ensino de matemática em seus países membros. Além do levantamento de informações, a OECE patrocina um encontro para discutir os dados obtidos, com vistas à promoção de uma reforma curricular do ensino de matemática. De fato, ele é realizado no Cercle de Royaumont, em Asnièressur-Oise, França, com a duração de duas horas semanais e com a participação de cerca de cinquenta delegados de dezoito países (GUIMARÃES, 2007, p. 2122).

Ao final do que fica conhecido como Seminário de Royaumont, temse uma proposta de reforma para o ensino de matemática, detalhada no ano seguinte, com a elaboração do texto Un programme moderne de mathématiques pour l'enseignement secondaire:

[a proposta] [...] foi fortemente influenciada pelas ideias estruturalistas dominantes na época, em particular no que 
se refere à Matemática e à Psicologia. Em relação à esta última, o trabalho de Jean Piaget assumiu uma visibilidade significativa no Seminário de Royaumont, sendo disso indício, nomeadamente, a menção de Marshal Stone, que presidiu aos trabalhos do seminário, às pesquisas de Piaget, destacando-se entre as que, em sua opinião, deram origem a 'possibildade (até então) desconhecidas em pedagogia', bem como a intervenção de Gustave Choquet sobre o ensino dos números e das operações que seguiu de perto as ideias de Jean Piaget sobre a gênese do número na criança (GUIMARÃES, 2007, p. 22).

Na leitura do Rapport sur le Séminaire de Royaumont, que apresenta um resumo da exposição de Gustave Choquet, tem-se uma reflexão baseada em Jean Piaget, sobre o tratamento da aritmética para o ensino nos primeiros anos escolares. E ela é relatada na forma de passos a serem seguidos, na abordagem do sistema de numeração: utilização de algum material adaptado ao ensino, como por exemplo, o material Cuisenaire. Com ele, diz Choquet, é possível levar o aluno à noção de número cardinal e de número ordinal (OECE, 1961, p. 67).

Aproximadamente dez anos mais tarde da proposição de um programa moderno para a matemática escolar em nível secundário, ganha divulgação um programa para o nível primário, para a escola elementar, para os primeiros anos escolares. Ele, segundo seus autores, é resultado de pesquisas e experiências realizadas, durante uma década, pelo International Study Group for Mathematics Learning - ISGML ${ }^{10}$. À frente da proposta, Zoltan Paul Dienes ${ }^{11}$.

Zoltan Dienes, Claude Gaulin e Dieter Lunkenbein, através do Centre de Recherches en Psycho-mathématique da Universidade de Sherbrooke, Canadá, publicam, em 1969, o texto "Un programme de mathématique pour le niveau élémentaire", no Bulletin de l'Association Mathématique du Québec".

\footnotetext{
${ }^{10}$ Centro de estudos responsável pela coordenação de grupos espalhados por diversos países, com o objetivo de desenvolver pesquisas sobre a maneira de se conseguir uma compreensão universal da matemática, fundamentada na psicologia teórica e na pedagogia prática (DIENES, 1967, p.09).

${ }^{11}$ Zoltan Paul Dienes tem em sua formação estudos de matemática pura e aplicada, com graduação pela Universidade de Londres, em 1937, doutorando-se pela mesma universidade, em 1939. Depois de larga experiência docente, transforma-se em pesquisador do Centro de Estudos Cognitivos da Universidade de Harvard (1960-61) e professor associado de Psicologia na Universidade de Adelaide (Austrália) (1961-64). Posteriormente, dirige o Centro de Psicomatemática em Sherbrooke no Québec (1964-1975). Em 1964, funda o International Study Group for Mathematics Learning (ISGML). (Disponível em: http://www.dienes.hu/page_biographies_DZ.html Acesso em: 9 jan. 2012) ${ }^{12} \mathrm{O}$ próprio artigo, em rodapé, informa que, simultaneamente, a proposta é publicada na Suiça, através da revista "Math-École" e na Alemanha, por "Der Unterricht in der Grundschule".
} 
Para os autores da proposta, o desafio é ter em conta o "estado atual da Matemática e os mais recentes desenvolvimentos da psicogênese" (DIENES et al., 1969, p. 29). O estágio atual da Matemática é contemplado, considerandose o acento no ensino das estruturas matemáticas. De outra parte, a psicogênese refere-se às contribuições de Jean Piaget. Com elas, Zoltan Dienes desenvolve uma sistematização teórica sobre como as crianças aprendem um conceito matemático: há seis estágios de aprendizagem. Tais estágios correspondem, no âmbito da aprendizagem matemática, "por assim dizer, o desenvolvimento em escala microscópica da teoria de Piaget” (DIENES et al., 1969, p. 43).

A proposta de um programa moderno para o ensino elementar leva em conta quatro caminhos que devem ser seguidos paralela e progressivamente: o caminho algébrico, o aritmético, o lógico e o geométrico.

Para o ensino do sistema de numeração, por exemplo, perseguir paralela e progressivamente significa, algebricamente: iniciar os ensinos com noções conjuntistas, diagramas de Venn ou de Carroll; aritméticamente: trabalhar a aprendizagem de número natural a partir das noções de conjunto; logicamente: considerar as propriedades e atributos dos objetos ou conjuntos de objetos; geometricamente: considerar noções de topologia (DIENES et al., 1969).

Conjuntos, conjuntos e conjuntos... E, como tratar, de modo elementar, a teoria dos conjuntos, condutora da proposta? Como introduzir as crianças na matemática estrutural?

Através de múltiplas atividades, os alunos se encontrarão em presença de coleções de objetos concretos (blocos, bolas, cartas etc) ou de suas representações gráficas. É, a princípio, sobre esses objetos ou representações, que eles levarão a bom termo, as operações de reunião, intersecção etc. (DIENES et al., 1969, p. 32).

As consequências dessas observações conduzem aos blocos lógicos, ícone das contribuições de Zoltan Dienes ${ }^{13}$.

\footnotetext{
${ }^{13}$ Os blocos lógicos constituem pequenas peças geométricas divididas em quadrados, retângulos, triângulos e círculos que tem por finalidade de uso levar as crianças a realizarem classificações de acordo com diferentes critérios (forma, cor, espessura) para definir os conjuntos materializados por essas peças, entre os materiais que são semelhantes. Com isso, parte-se para a exploração de noções como as de reunião, intersecção etc. Nos primeiros ensinos de matemática o número é construído a partir de coleções de objetos feitas a partir do critério de equipotência, aonde os alunos venham a descobrir que $\langle 5\rangle$, por exemplo, representa a classe de equivalência de todas as coleções equipotentes contendo cinco objetos.
} 


\section{Circulação e apropriação de um modelo cultural: a modernidade da matemática para crianças}

Estudos mostram que os textos de Jean Piaget são inicialmente utilizados no Brasil no âmbito da Escola Nova. A circulação inicial dos trabalhos desse autor incluem-no como um teórico partidário da escola ativa, mesmo que suas investigações não o identifiquem como um pedagogo. E ele, de fato, não se volta para propostas educacionais. A leitura escolanovista de Piaget refere-se à sua defesa do princípio da atividade na aprendizagem ${ }^{14}$. No entanto, no dizer de Mário Sérgio Vasconcelos,

apesar do interesse dos educadores brasileiros em se atualizar e promover mudanças pedagógicas em direção a uma educação moderna, as alterações oriundas dos métodos ativos ficaram mais "no papel" e tiveram poucas consequências inovadoras na prática escolar (VASCONCELOS, 1996, p. 67).

Relativamente ao foco deste trabalho - as mudanças da matemática escolar e o conceito de número - observa-se uma primeira apropriação dos estudos piagetianos, nos textos do professor Onofre Penteado Júnior. Em 1958, é publicado na Revista de Pedagogia - órgão editado pelos professores da Universidade de São Paulo, especificamente da antiga Cadeira de Didática Geral e Especial da Faculdade de Filosofia, Ciências e Letras - o artigo "O ensino do Cálculo", desse professor. Ao que tudo indica, o texto é um dos primeiros trabalhos escritos em revistas pedagógicas, que anuncia novos tempos para as práticas pedagógicas da Matemática no ensino primário. Nele, o autor aborda diretamente o tratamento do conceito de número, a partir de referências a Jean Piaget:

Há várias teorias a respeito de como se constroi, na mente da criança, o conceito de número. O ponto de vista racionalista admite o número como pura criação do espírito. O intuicionismo pestaloziano, como fruto do contar coisas, como uma impressão sensível. Em nossos dias Piaget vem estudando profundamente o assunto e em sua obra "L'Épistemologie génétique", edição de 1950, apresenta os resultados de anteriores pesquisas psicológicas, de grande interesse para a didática do cálculo. A construção do número

\footnotetext{
14 "Esse princípio indica que a atividade pedagógica deve respeitar e estimular as tendências ativas do desenvolvimento da própria criança. Nessa perspectiva a criança é concebida como um ser ativo, cuja ação, regida pela lei do interesse ou da necessidade, só poderá chegar ao pleno rendimento se forem despertados nela os motivos autônomos dessa atividade" (VASCONCELOS, 1996, p. 20).
} 
não se faz apenas empiricamente, isto é, o número não resulta da observação e comparação de objetos concretos, não é um dado fornecido a partir das coisas reais existentes no mundo exterior, e nem um produto do espírito, sem ligações com o mundo objetivo. A construção do conceito de número é o resultado da ação conjunta do espírito, da atividade mental que trabalha sobre a realidade do mundo exterior (PENTEADO JÚNIOR, 1958, p. 1).

Assim, evocando os trabalhos do epistemólogo suíço, o discurso direcionado aos professores tem por objetivo, ao mesmo tempo que anunciar o novo, a modernidade do ensino de matemática, também sepultar outras épocas, outros movimentos pedagógicos que construíram, no tempo, diferentes conceituações, na matemática escolar, para o ensino de número. Longe deverá ficar o tempo da memorização das tabuadas. Distante, também, a pedagogia do ensino intuitivo, onde número deveria ser aprendido com a lição das coisas, pela observação sensível delas.

De outra parte, talvez, um dos estudos de maior penetração junto aos professores de matemática, ligados às transformações da matemática escolar, em direção aos cânones estruturalistas, de autoria de Piaget, seja o texto por ele publicado no livro L'Enseignement des Mathématiques, de 1955, mencionado anteriormente. De acordo com a pesquisadora Elisabete Zardo Búrigo, "o livro teve repercusão internacional e foi divulgado no Brasil no II Congresso Nacional de Ensino da Matemática, em 1957” (BÚRIGO, 1989, p. 72).

Os estudos psicogenéticos de Piaget, que subsidiam uma nova matemática, uma matemática escolar das estruturas, no entanto, terão maior visibilidade ainda, na comunidade dos professores de matemática, por orientações de outros personagens. Depois de um primeiro momento de apropriação dos estudos de Jean Piaget, começam a circular no Brasil, direcionados à escola de primeiras letras, estudos de diversos autores. Dentre eles, destaca-se Zoltan Dienes.

A proposta de um novo programa de matemática para os anos iniciais da escolaridade, encabeçada por Dienes, é traduzida para o português e subsidia cursos para professores dados pelo Grupo de Estudos do Ensino da Matemática ${ }^{15}$. $\mathrm{Na}$ forma de apostila, o documento é traduzido por Anita Rondon Berardinelli. Essa referência de base para propostas ao ensino de matemática nos anos iniciais parece ter muita penetração nos meios educacionais, em específico, nos cursos

\footnotetext{
15 O GEEM - Grupo de Estudo do Ensino de Matemática tem atuação pioneira nos cursos de formação de professores com vistas à nova matemática das estruturas, à matemática moderna. O GEEM tem como liderança principal o professor Osvaldo Sangiorgi, que acaba por transformar-se em ícone do Movimento da Matemática Moderna no Brasil. Fundado em 1961, com sede na Universidade Mackenzie, o Grupo consegue apoio oficial para suas ações de formação, disseminando um novo currículo para o ensino de matemática, antes mesmo da oficialização da Matemática Moderna transformar-se em referência para os cursos primário e secundário (LIMA, 2006).
} 
de atualização sobre o ensino de matemática para a escola elementar e na elaboração de documentos oficiais curriculares ${ }^{16}$.

Os trabalhos de Zoltan Dienes são divulgados, especialmente, pelas professoras Lucília Bechara Sanchez ${ }^{17}$, integrante do GEEM, de São Paulo, e Ester Grossi ${ }^{18}$, por meio do Grupo de Estudos sobre o Ensino de Matemática, de Porto Alegre - GEEMPA ${ }^{19}$. Ambas fazem parte do Grupo presidido por Zoltan Dienes, o ISGML ${ }^{20}$.

\section{O engajamento da imprensa, sobretudo os jornais em São Paulo, dá bem} a ideia de como circulam as novas propostas para ensino de matemática nos anos iniciais. As ações com professores, pari passu são noticiadas:

Losangos, círculos, quadrados e retângulos plásticos, de várias cores e espessuras: são os blocos lógicos, base do ensino da Matemática Moderna. Seu principal objetivo: o desenvolvimento do raciocínio da criança, facilitando seu

\footnotetext{
${ }^{16}$ A pesquisa de Denise França (2007, p. 203) sobre orientações curriculares em São Paulo conclui que esses documentos oficiais levam ao professorado as orientações de Zoltan Dienes. Da mesma forma, em estudo mais específico, CHISTE (2010) mostra a influência direta dos trabalhos de Dienes na elaboração dos Guias Curriculares de São Paulo.

${ }^{17}$ Natural de Bragança Paulista, interior de São Paulo, formada pela PUC-Campinas - Pontifícia Católica de Campinas, mestre e doutora pela Faculdade de Educação da Universidade de São Paulo, iniciou sua vida profissional na rede pública de ensino, em 1958. No âmbito brasileiro, teve um papel relevante na escolarização da Matemática nas séries iniciais, pois parece ter sido uma das primeiras a trazer para as salas de aula paulistas as concepções do educador Zoltan Dienes (FRANÇA, 2011)

${ }^{18}$ Esther Pillar Grossi nasceu em 24 de abril de 1936, em Santa Maria, município situado no centro do estado do Rio Grande do Sul. Já residindo em Porto Alegre, em 1955, iniciou seus estudos em nível superior no curso de Matemática, na Pontifícia Universidade Católica (PUCRS), concluiu o Bacharelado em 1957 e a Licenciatura em 1958. Em 1968, mudou-se para a França, onde cursa o mestrado na Faculté des Sciences - Université de Paris V, obtendo créditos em Topologia, Álgebra, Lógica e Psicologia. Em 1970, já de volta a Porto Alegre, juntamente com mais 49 professores, fundou o GEEMPA (FISCHER; SANTOS, 2011).

${ }^{19}$ No Rio Grande do Sul, desde 1964, há cursos e seminários ofertados a professores primários e secundários versando sobre Matemática Moderna. Em destaque, a partir de 1970, ano de sua fundação, os trabalhos realizados pelo GEEMPA, liderado por Esther Grossi. O Grupo prossegue suas ações de formação com a nova matemática até 1983, quando altera suas perspectivas de trabalho, passando a ter a mesma sigla, mas com a designação de Grupo de Estudos sobre Educação, Metodologia de Pesquisa e Ação. O GEEMPA organiza e orienta estudos com classes-piloto em turmas de $1^{\circ}$. Grau a partir de 1972, com base na metodologia apregoada por Zoltan Dienes (FISCHER, 2006), (FISCHER; CARPES, 2007), (FISCHER; PINTO, 2011).

${ }^{20}$ Além destas duas educadoras participam do Grupo: Maria do Carmo Villa (Belo Horizonte), Ione Halser (Brasília), Dione Lucchesi de Carvalho (São Paulo), Maria Lucia Martins (Rio de Janeiro), Judy Galper (Rio de Janeiro) e Osvaldo Sangiorgi (São Paulo). Os projetos experimentais sobre o ensino de matemática para as series iniciais desenvolvidos por estes educadores são apresentados nas sessões sul-americanas do ISGML por meio de relatórios. Os encontros dos membros do ISGML têm por finalidade a discussão de processos de aprendizagem matemática, a formação de professores, a elaboração de currículos e o planejamento de ações concretas na área. Trata-se de um espaço destinado a discussão de práticas de ensino de matemática que estão sendo aplicadas pelos membros do Grupo em suas instituições de origem. Tais práticas são provenientes das experiências realizadas por Dienes e sistematizadas no âmbito do ISGML (APLBS/GHEMAT).
} 
aprendizado. Juntamente com outras técnicas e métodos de ensino de matemática, foram apresentados no curso de atualização para professores primários, que está sendo promovido pelo Grupo de Estudos e Ensino de Matemática, da Universidade Mackenzie (JORNAL O ESTADO DE SÃO PAULO, 8 jul. 1970)

Depois deste preâmbulo, o texto apresenta uma entrevista com a professora Lucília Bechara Sanchez, que sintetiza o curso de atualização para professores primários: "a orientação do curso é baseada na apresentação de atividades que visem a formação de conceitos [...]".

Junto aos cursos de atualização e às atividades desenvolvidas com grupos de professores, vão tendo penetração e circulação, também, os livros de Dienes. Um dos mais divulgados é “A Matemática Moderna no Ensino Primário”. Já em suas páginas iniciais, diz o autor:

O número é uma abstração. Os números não têm existência real, são simples propriedades; mas são propriedades dos conjuntos de objetos, e não dos próprios objetos. A propriedade que se designa pela palavra "dois" não poderá aplicar-se nunca a objetos determinados, a acontecimentos ou entes (de qualquer natureza), mas tão somente a conjuntos de objetos, acontecimentos, entes. Esta é a razão da existência do "universo dos conjuntos", intermédio entre o universo dos objetos e o dos números. (DIENES, 1967, p.16)

Os novos tempos do ensino de matemática transformam em ícone da modernização desse ensino, a Teoria dos Conjuntos. Ela constitui elemento primeiro e fundamental para conduzir o aluno à aprendizagem da Matemática Moderna. Sem ela, não há possibilidade do ensino-aprendizagem do conceito de número, como bem reforça Esther Grossi, num de seus vários textos divulgados na imprensa e em seus livros:

O conjunto e os alunos. - Antes da abordagem do conceito de número cardinal, que é muito complexo, é necessário que aos alunos sejam oportunizadas atividades sobre conjuntos. Ora, a teoria de conjuntos elaborada por Cantor, na segunda metade do século passado, foi de extrema fecundidade no sentido da unificação dos diversos ramos da matemática, provocando a reorganização de todo o arcabouço desta ciência. Entretanto, ninguém pensou como 
ela poderia ser estudada por crianças, ainda mais de seis, sete anos, na primeira série do ensino fundamental (GROSSI, 1971).

Grossi escreve e divulga as novas concepções sobre o ensinoaprendizagem de número, em periódicos pedagógicos, principalmente na Revista do Ensino, com o apoio da Secretaria de Educação e Cultura do Rio Grande do $\mathrm{Sul}^{21}$.

Outros estados brasileiros também fazem circular a nova matemática para os anos iniciais. E, neste caso, as revistas destinadas aos professores assumem papel importante ${ }^{22}$.

Para além das orientações veiculadas pelas revistas pedagógicas, dos cursos de atualização de grupos de professores, da circulação enorme de artigos na imprensa ${ }^{23}$, a nova matemática ganha, também, novos livros didáticos. Um dos pioneiros é a obra "Curso Moderno de Matemática para a Escola Elementar", escrito por Lucília Bechara Sanchez, em parceria com as professoras Manhúcia Liberman e Anna Franchi. O texto, em primeira edição, é publicado em 1967 pela Companhia Editora Nacional. No primeiro volume, como primeira parte da matemática escolar, está o "Período preparatório para os conceitos matemáticos", conforme expressão do Prefácio da obra. Trata-se do trabalho com elementos da Teoria dos Conjuntos. Pranchas e pranchas coloridas e por colorir levam a criança a fazer correspondência e ordenação com cor, forma, tamanho, de enorme multiplicidade de desenhos representativos da figura humana, de animais, de formas geométricas etc. Aproximadamente metade das 120 páginas do livro antecedem o tratamento do sistema numérico. Pesquisas mostram que essa produção didática teve enorme penetração nas escolas brasileiras ${ }^{24}$.

\footnotetext{
${ }^{21}$ A tese de doutoramento de Luiz Henrique Ferraz Pereira (2010) analisa os artigos sobre o ensino de matemática publicados nesse periódico, entre as décadas 1950 e 1970, mostrando, dentre outras coisas, como se dá a penetração do ideário da Matemática Moderna no ensino primário, através dos discursos veiculados pela Revista.

${ }^{22}$ A pesquisa de Rosimeire Borges (2011) analisa, dentre vários periódicos, a circulação do ideário modernista da matemática na revista AMAE Educando do Instituto de Educação de Minas Gerais.

${ }^{23}$ É objeto de investigação do pesquisador Mário Nakashima (2007) o modo de circulação das novas propostas para ensino da Matemática Moderna através dos jornais de São Paulo. Seu estudo traz um precioso inventário de cerca de 350 artigos, publicados entre 1954 e 1980.

${ }^{24}$ A tese de doutoramento de Lucia Villela (2009), que toma como uma das fontes, o arquivo da Cia. Editora Nacional revela a importância das obras didáticas dessas autoras. Com a publicação desse primeiro livro, abriu-se um rol de publicação de outros volumes, associando outras professorasautoras, que alcançaram tiragens que ultrapassam a casa de quatro milhões de exemplares vendidos! De outra parte, o estudo da pesquisadora Maria Célia Leme da Silva, sobre os programas de ensino de matemática elaborados para os primeiros anos escolares, no estado de São Paulo, revela que o Programa de 1968, que oficializa a Matemática Moderna, tem como membro de sua elaboração a professora Manhúcia Liberman. Esse é mais um elemento que favorece a ampla aceitação da coleção didática "Curso Moderno de Matemática para a Escola Elementar" (LEME DA SILVA, 2011, p. 12).
} 
Consolida-se, em termos de publicações, orientações pedagógicas aos professores, programas de ensino e livros didáticos, uma nova matemática para crianças. Sedimenta-se um novo discurso orientador de práticas pedagógicas a serem realizadas no ensino de matemática para os primeiros anos escolares. Cria-se uma nova "cultura de ensino de matemática", segundo a expressão elaborada pela pesquisadora Joseane Pinto de Arruda (2011, p. 67) ${ }^{25}$. Para esses novos tempos, número é considerado um conteúdo muito complexo para ser tratado como primeiro tema de estudos. Novos conteúdos elementares devem ganhar prioridade e anteciparem-se ao tratamento do sistema de numeração. Esses novos conteúdos elementares referem-se à Teoria dos Conjuntos. Número não se memoriza, não se sente e nem tampouco é fruto de experiência das crianças com problemas da vida real. Número é propriedade de conjuntos.

\section{Considerações finais}

Como entender as transformações no ensino de matemática para as primeiras séries escolares? Como a modernidade do ensino de matemática afirma-se no meio escolar? Como as transformações do conceito de número, na Aritmética, são reveladoras das dinâmicas de modificação do saber escolar? Todas essas questões podem ser respondidas, ao menos parcialmente, a partir da resposta à questão orientadora deste estudo: que alteração sofre, na matemática escolar brasileira, o conceito de número, a partir do final da década de 1950 ?

Os preâmbulos da modernidade do ensino da Aritmética para crianças mostram que vagas pedagógicas são responsáveis diretas pelas alterações no modo de conceber o que é número para as séries iniciais. Parte-se de um tempo onde número é a memória do cantar a tabuada; passa-se pelas lições que as coisas podem dar sobre numeração e chega-se às ideias escolanovistas, onde a resolução de problemas da vida real das crianças pode levar à aprendizagem de número. Em todas essas épocas, tem-se, logo ao início dos trabalhos escolares, o tratamento do conceito de número. Ele é o primeiro tema de estudos da matemática para crianças.

A modernidade altera completamente essa organização de ensino. A

\footnotetext{
${ }^{25}$ ARRUDA (2011, p. 67) estuda a constituição de uma "cultura de ensino de matemática moderna na escola primária" investigando as transformações que ocorrem no Colégio de Aplicação da Universidade Federal de Santa Catarina, entre as décadas de 1960-70. Na pesquisa, revela o surgimento de novas "marcas, regras e costumes" para o ensino de matemática no cotidiano escolar dos anos iniciais de escolarização.
} 
análise da trajetória de modificação da matemática escolar para crianças, a partir de finais da década de 1950, revela o amparo de um movimento internacional - o Movimento da Matemática Moderna - como sustentação para os discursos e práticas da modernidade no ensino da Aritmética escolar. Esse Movimento conjuga transformações na Matemática propriamente dita, e a afirmação de trabalhos da psicologia cognitivista. Ambos imersos num tempo de predomínio do estruturalismo, como modo de pensar a produção científica. Tratase de uma vaga pedagógica com características diferentes das anteriores. Os estudos e ações dos matemáticos, de grupos de matemáticos, têm papel fundamental nas transformações da matemática escolar. E não se trata somente da matemática escolar de níveis próximos ao ensino universitário: está em questão a matemática para crianças, aquela dos primeiros anos escolares. Como resultado desse contexto, a organização curricular e o ensino de matemática para crianças sofre transformação radical: número não poderá mais ser ensinado logo ao início da escolaridade. Número é elemento abstrato, que deve ficar longe das crianças, em seu primeiro contato com a Matemática. Número é propriedade. E, neste caso, altera-se a ordem vigente há séculos. Desse modo, para os primeiros contatos escolares da criança com a matemática está reservada a Álgebra e não mais a Aritmética. No princípio são as relações, depois os números. A aproximação com os elementos algébricos, que decorre, até então, na escola elementar, de uma generalização da Aritmética é abandonada. Passa ao primeiro plano, a Álgebra, a ser seguida pela Aritmética. As estruturas algébricas para crianças em seus primeiros elementos passam a constituir-se em novos conteúdos para o currículo escolar, de maneira a ser possível ensinar número. E, esses outros conteúdos, constituem novos elementares - entendidos como novas formas basilares do conhecimento - uma nova matemática escolar, portanto que permite o acesso ao conceito de número, à sua caracterização como uma propriedade dos conjuntos. Os novos conteúdos elementares são construídos a partir da Teoria dos Conjuntos. Com ela, ao tempo do Movimento da Matemática Moderna, sustenta-se a ideia da aprendizagem do novo conceito escolar do que é número. Primeiro o ensino de elementos da Teoria dos Conjuntos; depois, os números. E os conjuntos constituem ícone desse tempo escolar: um tempo em que a escola do ler, escrever e contar transforma-se na escola do ler, escrever e trabalhar com conjuntos. O contar, o ensino do sistema de numeração, não mais é o primeiro conteúdo da matemática para crianças, ele é substituído pelos conjuntos. Primeiro a Álgebra, depois a Aritmética.

Diferentemente das vagas pedagógicas anteriores a modernidade da 
matemática escolar para crianças parece ter sido engendrada por caminhos que, de certo modo, apartam Matemática e Pedagogia. No encontro da Psicologia e da Matemática, a Pedagogia parece ter sido a última a ser chamada no processo modernizador. Algo distanciada de outras matérias e disciplinas presentes na cultura escolar, o ensino da Matemática Moderna nas escolas, ao que parece, constitui-se num estranho no ninho da cultura escolar. Assim, é possível compreender a razão pela qual a historiografia da educação pouca importância dá à vaga pedagógica estruturalista da matemática escolar para crianças e adolescentes.

\section{Referências}

ACZEL, A. D. El artista y el Matemático: La historia de Nicolas Bourbaki, el genio matemático que nunca existió. Barcelona, Espanha: Gedisa Editorial, 2009.

ALBUQUERQUE, I. Metodologia da Matemática. 4. ed., Rio de Janeiro: Conquista. 1960.

APLBS/GHEMAT - Arquivo Pessoal Lucília Bechara Sanchez. Osasco, SP: Centro de Documentação do Grupo de Estudos de História da Educação Matemática. Disponível em: <http://www.unifesp.br/centros/ghemat/images/stuffs/ APLBS_Planilha.pdf>.Acesso em: 07 nov. 2012.

ARRUDA, J. P. Histórias e práticas de um ensino na escola primária: marcas e movimentos da Matemática Moderna. 2011. 312f. Tese (Doutorado em Educação Científica e Tecnológica) - Centro de Ciências Biológicas. Centro de Ciências da Educação. Programa de Pós-Graduação em Educação Científica e Tecnológica, Universidade Federal de Santa Catarina, Florianópolis. 2011.

BARBOSA, R. Reforma do Ensino Primário e várias instituições complementares da Instrução Pública. Obras Completas de Rui Barbosa. Vol. X, Tomo II. Rio de Janeiro: Ministério da Educação e Saúde, 1946.

BORGES, R. A. S. Circulação e apropriação do ideário do Movimento da Matemática Moderna nas séries iniciais: as revistas pedagógicas no Brasil e em Portugal. 2011. 245f. Tese (Doutorado em Educação Matemática) - Programa de Pós-Graduação em Educação Matemática, São Paulo: UNIBAN, 2011.

BREINER, Z. Q. Algumas considerações sobre o ensino de Aritmética. Revista Brasileira de Pedagogia. Rio de Janeiro: Confederação Católica Brasileira de Educação, Ano I, n. 9-10, 1934. 
BÚRIGO, E. Z. Movimento da Matemática Moderna: estudo da ação e do pensamento de educadores matemáticos dos anos 60. 1989. 195f. Dissertação (Mestrado em Educação) - Faculdade de Educação, Universidade Federal do Rio Grande do Sul. Porto Alegre. 1989.

CARVALHO, M. M. C. Pedagogia da Escola Nova, produção da natureza infantil e controle doutrinário da escola. In: FREITAS, M. C.; KULMANN JR, M. (Orgs.) Os intelectuais na história da infância. São Paulo: Cortez, 2002. p. 373-408.

CHARTIER, R. A história cultural - entre práticas e representações. Rio de Janeiro: Editora Bertrand Brasil S. A., 1990.

CHARTIER, R. La historia o la lectura del tempo. Barcelona: Editorial Gedisa, 2007.

CHERVEL, A. História das disciplinas escolares: reflexões sobre um campo de pesquisa. Teoria \& Educação, Porto Alegre, v. 2, n. 2, p. 177-229, 1990.

CHISTE, L. Dienes e os guias curriculares de São Paulo da década de 1970: um estudo sobre as influências. 2010.143f. Dissertação (Mestrado em Educação Matemática) - Programa de Pós-Graduação em Educação Matemática. Universidade Bandeirante de São Paulo. São Paulo. 2010.

COSTA, D. A. A Aritmética escolar no ensino primário brasileiro, 1890-1946. 2010. 279f. Tese (Doutoramento em Educação Matemática) - Programa de Pós-Graduação em Educação Matemática, São Paulo: Programa de Estudos Pós-Graduados em Educação Matemática. Pontifícia Universidade Católica de São Paulo. São Paulo. 2010.

DIENES, Z. P. A Matemática Moderna no Ensino Primário. Brasil: Livros Horizonte Ltda., 1967.

DIENES, Z. P.; GAULIN, C.; LUNKENBEIN, D. Un programme de mathématique pour le niveau élémentaire. Bulletin de l’A. M. Q., Université de Laval, Québec, automne et hiver, 1969.

DOSSE, F. Histoire du Structuralisme. Tome 1. Paris: Éditions La Découverte, 1992.

ESTADO DE SÃO PAULO [jornal]. Estes blocos ensinam tudo. 8 jul. 1970.

FISCHER, M. C. B. A experiência das classes-piloto organizadas pelo GEEMPA, ao tempo da Matemática Moderna. Revista Diálogo Educacional, Curitiba, PR: Programa de Pós-Graduação em Educação - PUCPR, v. 6, n. 18, p. 101-112, 2006. 
FISCHER, M. C. B.; CARPES, F. Reformulação metodológica do ensino da Matemática no $1^{\circ}$. Grau: análise preliminar do Relatório de Pesquisa realizada pelo GEEMPA(1975). In: MATOS, J. M.; VALENTE, W. R. (Orgs.). A Matemática Moderna nas escolas do Brasil e de Portugal: primeiros estudos. São Paulo: Capes/Grices/Da Vinci, 2007. p. 97-123.

FISCHER, M. C. B.; PINTO, N. B. A Matemática Moderna e a formação de professores no Brasil. In: OLIVEIRA, M. C.A.; SILVA, M. C. L.; VALENTE, W. R. Movimento da Matemática Moderna: história de uma revolução curricular. Juiz de Fora, MG: Editora da UFJF, 2011. p. 87-108.

FISCHER, M. C. B.; SANTOS, M. B. A multicolorida professora Esther Grossi. Campinas: Mimeo. 2011.

FRANÇA, D. M. A. A produção oficial do Movimento da Matemática Moderna para o ensino primário do Estado de São Paulo (1960-1980). 2007. 272 f. Dissertação (Mestrado em Educação Matemática) Centro de Ciências Exatas e Tecnologia. São Paulo: Programa de Pós-Graduação em Educação Matemática, Pontifícia Universidade Católica de São Paulo. São Paulo. 2007.

FRANÇA, D. M. A. Lucília Bechara: a especificidade do MMM nas séries iniciais. Campinas: Mimeo. 2011.

GROSSI, E. P. O conjunto e os alunos. Jornal Correio do Povo. Porto Alegre, 20 jun. 1971.

GUIMARÃES, H. M. Por uma matemática nova nas escolas secundárias perspectivas e orientações curriculares da Matemática Moderna. In: MATOS, J. M.; VALENTE, W. R. (Orgs.). A Matemática Moderna nas escolas do Brasil e de Portugal: primeiros estudos. São Paulo: Editora Da Vinci, 2007.

LEME DA SILVA, M. C. Novo programa de ensino, novos livros didáticos: mudanças didático-pedagógicas no conceito de número no Curso Primário (1949-1968). In: REUNIÃO ANUAL DAANPEd, 34., 2011, Natal. Anais... Disponível em: <http:// 34reuniao.anped.org.br/images/trabalhos/GT19/GT19-153\%20int.pdf >. Acesso en: 31 jan. 2012.

\section{LIMA, F. R. GEEM Grupo de Estudos do Ensino da Matemática e a formação de} professores durante o Movimento da Matemática Moderna no Brasil. Departamento de Matemática. 2006. 129f. Dissertação (Mestrado em Educação Matemática) - Centro de Ciências Exatas e Tecnologia. São Paulo: Programa de Estudos Pós-Graduados em Educação Matemática da Pontifícia Universidade Católica de São Paulo. São Paulo. 2006. 
OECE. Mathématiques Nouvelles. Paris: OECE, 1961.

PATRAS, F. La pensée mathématique contemporaine. Paris: PUF, 2001.

PENTEADO JÚNIOR, O. A. O ensino do cálculo. Revista de Pedagogia, São Paulo: USP, Ano IV, v. 4, n. 8, p. 1-5, jul./dez., 1958.

PEREIRA, L. H. F. Os discursos sobre matemática na Revista do Ensino/RS (19501970). 2010. 245f. Tese (Doutorado em Educação) - Porto Alegre, RS: PUCRS, 2010.

PIAGET, J. et al. L'Enseignement des mathématiques. Suiça: Delachaux \& Niestlé S. A., 1955.

MIGUEL, A.; VILELA, D. S. Práticas escolares de mobilização de cultura matemática. Cad. Cedes, Campinas, v. 28, n. 74, p. 97-120, jan./abr., 2008.

NAKASHIMA, M. N. O papel da imprensa no Movimento da Matemática Moderna. 2007. 152f. Dissertação (Mestrado em Educação Matemática) - Programa de PósGraduação em Educação Matemática da Pontifícia Universidade Católica de São Paulo. São Paulo. 2007.

TANURI, L. M. O ensino normal no Estado de São Paulo, 1890-1930. Publicação da Faculdade de Educação. Estudos e Documentos. Universidade de São Paulo, 1979.

VASCONCELOS, M. S. A difusão das ideias de Piaget no Brasil. São Paulo: Casa do Psicólogo Livraria e Editora Ltda., 1996.

VILLELA, L. M. A. GRUEMA - uma contribuição para a história da educação matemática no Brasil. 2009. 223f. Tese (Doutorado em Educação Matemática) Programa de Pós-Graduação em Educação Matemática, UNIBAN, São Paulo. 2009.

Submetido em Abril de 2012. Aprovado em Maio de 2012. 
